\title{
Bibliometrical Analysis of the Smart Grid Research
}

\author{
Jinrong Zhu
}

School of Economics and Management, North China Electric Power University, Changping District, Beijing 102206, China

Keywords: The smart grid; Bibliometric analysis; Electric power system;

\begin{abstract}
Based on the information of 1924 articles collected from China Academic Journal Network Publishing Database (CAJD), bibliometrical analysis methods are used to analyze the smart grid research. The results showed that: 1) the smart grid has got the attention of many researchers, core authors have been initially presented; 2) The main research institutes of this field are the professional institute in electric power field and universities with electricity professional; 3) Automation of Electric Power Systems, East China Electric Power and Electrotechnical Application are the main journals publishing the articles about the smart grid; 4) "Demand response", "Power system" and "Internet of things" are the keywords frequently appeared, which are the research focuses in the field of smart grid.
\end{abstract}

\section{Introduction}

The smart grid has got the attention of many researchers and periodicals. They have discussed both the meaning and basic concept of the smart $\operatorname{grid}[1,2]$, and analyzed the relevant standard system [3].

For deep understanding of the smart grid research status and providing a reference for future research in this field, this article uses the bibliometrical method to analyze the related literature in China Academic Journal Network Publishing Database, which include the distribution of publishing year, core authors, core research institutions, core journals, the high frequency keywords, etc.

\section{Data Sources and Processing}

This paper is based on the platform of China Academic Journal Network Publishing Database (CAJD). When seeking the effective information, journals sources are "core journals" and "CSSCI journals", search word is "smart grid", field is "subject", the match method is "precise", time span is "until 2015". Based on the retrieval on March 10, 2016, a total of 2638 records are found. Excluding the articles without author and signed by "editorial board", "this Journal Dispatch", finally 1924 effective records are collected.

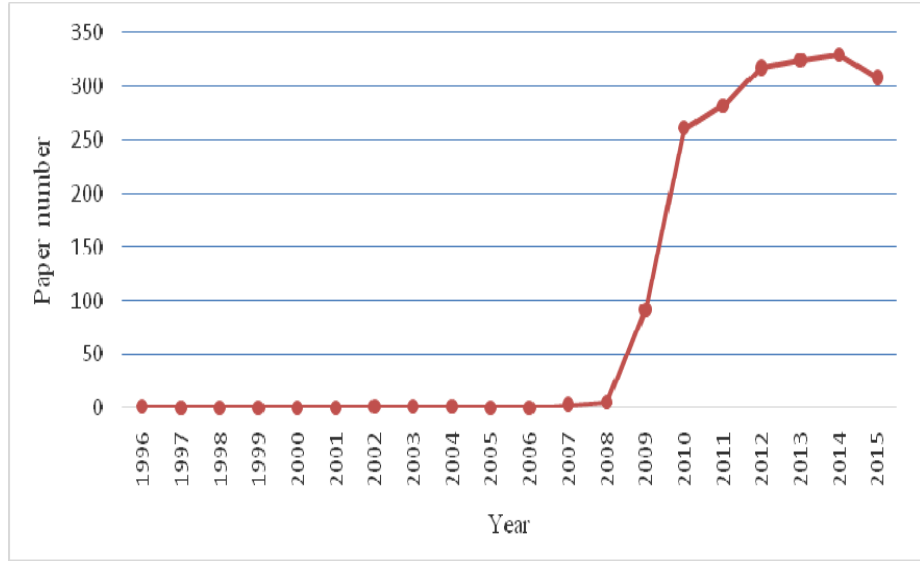

Figure 1 Smart Grid Research Paper Growth Line

The smart grid research publications in each year are shown in table 1. Table 1 indicates that the research paper quantity of the smart grid in the first 11 years is very small, only $0 \sim 1$ article for every year. In 2009, the publication number soared to 91. From 2010 to 2015, it was stable at 
around 300 articles each year. This indicates that this field has got more and more attention of the researchers, and it has gained steady development. The line chart of publications in each year is shown in figure 1.

Table 1 Quantity Statistics of the Smart Grid Research Publications in Each Year

\begin{tabular}{|c|c|c|c|}
\hline Year & Paper number & Year & Paper number \\
\hline 1996 & 1 & 2006 & 0 \\
\hline 1997 & 0 & 2007 & 3 \\
\hline 1998 & 0 & 2008 & 5 \\
\hline 1999 & 0 & 2009 & 91 \\
\hline 2000 & 0 & 2010 & 261 \\
\hline 2001 & 0 & 2011 & 282 \\
\hline 2002 & 1 & 2012 & 317 \\
\hline 2003 & 1 & 2013 & 324 \\
\hline 2004 & 1 & 2014 & 329 \\
\hline 2005 & 0 & 2015 & 308 \\
\hline
\end{tabular}

\section{The analysis of authors, institutions, and journals}

The Core Author Analysis. Statistics shows that there are 6578 authors in all 1924 articles, cooperative degree is 3.42. These papers involved 4545 authors (This article did not consider the duplicate of names). Ming Zeng is the author that has the most publications with 31 articles, the second and third respectively are Xinjie Li (18 articles), and Junyong Liu (17 articles). The authors with 11 published articles or above are shown in table 2. In addition, there are 3524 authors only published 1 article, and it accounts for $77.5 \%$ of the total number of authors.

Table 2. Core Authors in the Smart Grid Study

\begin{tabular}{|c|l|c|c|l|c|}
\hline No. & Author & Paper number & No. & Author & Paper number \\
\hline 1 & Ming Zeng & 31 & 10 & Dong Liu & 12 \\
\hline 2 & Xinjie Li & 18 & 11 & Yang Cao & 12 \\
\hline 3 & Junyong Liu & 17 & 12 & ShengWei Mei & 12 \\
\hline 4 & Jianguo Yao & 16 & 13 & Yusheng Xue & 12 \\
\hline 5 & Hongbin Sun & 15 & 14 & Chuangxin Guo & 12 \\
\hline 6 & Zheng Yan & 13 & 15 & Guangyu He & 11 \\
\hline 7 & Fushuan Wen & 13 & 16 & Yijia Cao & 11 \\
\hline 8 & Peng Li & 13 & 17 & Qian Ai & 11 \\
\hline 9 & Shengchun Yang & 13 & 18 & Song Xue & 11 \\
\hline
\end{tabular}

If the first author is the only consideration, core author distribution is shown in table 3 . From the comparison between table 3 and table 2, if the first authors are the only consideration, the most publication authors are still Ming Zeng and Xinjie Li, but the list after them will be more different. There are only 5 authors in table 2 appeared in table 3 .

Table 3. Core Authors in the Smart Grid Study (First Author)

\begin{tabular}{|c|l|c|c|l|c|}
\hline No. & Author & Paper number & No. & Author & Paper number \\
\hline 1 & Ming Zeng & 22 & 11 & Xiangping Meng & 5 \\
\hline 2 & Xinjie Li & 18 & 12 & Baohui Zhang & 5 \\
\hline 3 & Haijiang Shi & 7 & 13 & Hui Xu & 5 \\
\hline 4 & Jiaqing Zhao & 7 & 14 & Fan Yang & 5 \\
\hline 5 & Lisha Zhou & 6 & 15 & ShengWei Mei & 5 \\
\hline 6 & Peng Li & 6 & 16 & Xingzhi Wang & 5 \\
\hline 7 & Guan Xiao & 6 & 17 & Bin Wang & 5 \\
\hline 8 & Yixin Yu & 5 & 18 & Dewen Wang & 5 \\
\hline 9 & Jing Lu & 5 & 19 & Mingjun Wang & 5 \\
\hline 10 & Jianguo Yao & 5 & 20 & Jia Ju & 5 \\
\hline
\end{tabular}


The Institution Distribution. Considering only the first institution of each article, China Electric Power Research Institute is the number 1 institution that has the most publications in the field of smart grid research with 150 articles, secondly and thirdly, respectively, are North China Electric Power University (147 articles), and Tsinghua University (74 articles). Institutions in the top 16 of publication list are shown in table 4 . Table 4 indicates that the core research institutions are mainly professional institutes in electric power field and excellent professional power universities. At the same time, some electric power enterprises also play important roles.

Table 4. TOP16 Institution List of Smart Grid Research Publications

\begin{tabular}{|c|c|c|c|c|c|}
\hline No. & Institution & Paper number & No. & Institution & Paper number \\
\hline 1 & $\begin{array}{lrr}\text { China Electric } & \text { Power } \\
\text { Research Institute } & \\
\end{array}$ & 150 & 9 & Tianjin University & 31 \\
\hline 2 & $\begin{array}{l}\text { North China Electric Power } \\
\text { University }\end{array}$ & 147 & 10 & Xi'an Jiaotong University & 30 \\
\hline 3 & Tsinghua University & 74 & 11 & Zhejiang University & 27 \\
\hline 4 & $\begin{array}{l}\text { Shanghai Jiaotong } \\
\text { University }\end{array}$ & 56 & 12 & Wuhan University. & 27 \\
\hline 5 & $\begin{array}{l}\text { Shanghai Municipal Electric } \\
\text { Power Company }\end{array}$ & 47 & 13 & Southeast University & 26 \\
\hline 6 & $\begin{array}{l}\text { State Grid Electric Power } \\
\text { Research Institute }\end{array}$ & 46 & 14 & $\begin{array}{l}\text { Chinese Academy of } \\
\text { Science }\end{array}$ & 24 \\
\hline 7 & Sichuan University & 33 & 15 & $\begin{array}{l}\text { Shanghai University of } \\
\text { Electric Power }\end{array}$ & 21 \\
\hline 8 & $\begin{array}{l}\text { East China power grid co., } \\
\text { LTD }\end{array}$ & 32 & 16 & $\begin{array}{l}\text { State Grid Energy Research } \\
\text { Institute }\end{array}$ & 19 \\
\hline
\end{tabular}

The Journal Distribution. Statistics show that 1924 articles were published in 225 journals, which demonstrates that smart grid research has gained the attention of many journals. The Automation of Electric Power Systems has the most publications (245 articles), followed by East China Electric Power (214 articles), and Electrotechnical Application (191 articles). Journals publishing above 22 articles are shown in table 5, these journals published totally 1388 articles, accounting for $72 \%$ of the total number of 1924 articles, indicating that smart grid research has formed special stable group in periodicals. The top 6 journals issued 1006 articles, accounting for $22 \%$ of all smart grid research articles, the proportion is very high, and they are the core journals in this field.

Table 5 Journal Distribution of Smart Grid Research Articles ( $\geq 22)$

\begin{tabular}{|c|c|c|c|}
\hline Journal Name & Number of Publications & Journal Name & Number of Publications \\
\hline $\begin{array}{lr}\text { Automation } & \text { of } \\
\text { Electric } & \text { Power } \\
\text { Systems } & \\
\end{array}$ & 245 & Electric Power & 90 \\
\hline $\begin{array}{l}\text { East China Electric } \\
\text { Power }\end{array}$ & 214 & $\begin{array}{l}\text { Electric Power Automation } \\
\text { Equipment }\end{array}$ & 62 \\
\hline $\begin{array}{l}\text { Electrotechnical } \\
\text { Application }\end{array}$ & 191 & High Voltage Apparatus & 36 \\
\hline $\begin{array}{ll}\text { Power } & \text { System } \\
\text { Technology } & \\
\end{array}$ & 135 & $\begin{array}{l}\text { Chinese Journal of Power } \\
\text { Sources }\end{array}$ & 28 \\
\hline $\begin{array}{ll}\text { Power } & \text { System } \\
\text { Protection and Control }\end{array}$ & 118 & $\begin{array}{l}\text { Transactions of China } \\
\text { Electrotechnical Society }\end{array}$ & 26 \\
\hline $\begin{array}{l}\text { Electrical } \\
\text { Measurement } \quad \& \\
\text { Instrumentation }\end{array}$ & 103 & Low Voltage Apparatus & 23 \\
\hline $\begin{array}{l}\text { Proceedings of the } \\
\text { Chinese Society for } \\
\text { Electrical Engineering }\end{array}$ & 95 & High Voltage Engineering & 22 \\
\hline
\end{tabular}




\section{The Keywords Analysis}

From all the 1924 articles, a total of 4434 keywords appeared. Since using "smart grid" as the keyword to retrieve and obtain data, therefore the word "smart grid" occurrences is certainly the most, and it appeared totally 956 times. The top 14 high frequency keywords are shown in table 6 . Table 6 shows that "demand response", "power system" and "Internet of things" appeared more than 50 times, which are the research focuses in the field of smart grid.

Table 6 The High Frequency Keywords of the Smart Grid Research (Top 14)

\begin{tabular}{|c|l|c|l|l|c|}
\hline No. & Keywords & Frequency & No. & Keywords & Frequency \\
\hline 1 & The smart grid & 956 & 8 & Cloud computing & 44 \\
\hline 2 & Demand response & 57 & 9 & $\begin{array}{l}\text { Intelligent power } \\
\text { distribution network }\end{array}$ & 40 \\
\hline 3 & Electric Power Systems & 53 & 10 & The smart electricity meter & 39 \\
\hline 4 & The Internet of things & 51 & 11 & power distribution network & 39 \\
\hline 5 & Intelligent substation & 48 & 12 & Renewable energy & 36 \\
\hline 6 & Distributed power & 47 & 13 & Distributed generation & 34 \\
\hline 7 & The electric car & 47 & 14 & Micro power grid & 31 \\
\hline
\end{tabular}

\section{Conclusion}

Through the bibliometric analysis of journal articles in the field of smart grid, the following characteristics can be found in the study of this field:

1) The smart grid research has got the attention of many researchers and core authors initially presented.

2) The main research institutions are professional institutes in electric power field and excellent professional power universities. At the same time, some electric power enterprises also play important roles.

3) The Automation of Electric Power Systems, East China Electric Power and Electrotechnical Application are the main journals published the articles about the smart grid.

4) The frequency of the kewords "Demand response", "Power system" and "Internet of things" is very high, which are the research focuses in the field of smart grid.

\section{References}

[1] BI Tian-shu, LIU Su-mei, HUANG Zhen-yu, Nouredine Hadjsai, The implications and implementations of smart grid in different countries, Journal of North China Electric Power University, 38(2011),2, 1-9 (in Chinese)

[2] YU Yi-xin, LUAN Wen-peng, Basic Philosophy of Smart Grid, Journal of Tianjin University, 44(2011), 5, 377-384 (in Chinese)

[3] LIU Wen, YANG Hui-xia, ZHU Bin, Review of research on smart grid technical standard system, Power System Protection and Control, 40(2012),10,120-126 (in Chinese) 